\title{
A NOÇÃO DE SEMELHANÇA NO UNIVERSO POÉTICO E ARTÍSTICO DE RENÉ MAGRITT'TE*
}

\author{
Marcia Arbex** \\ Cidio Randolfo Geraldo Leite ${ }^{* * *}$
}

\begin{abstract}
Resumo: Tradução para o português do texto L'Art de la ressemblance (A arte da semelhança, 1979), do artista belga René Magritte, precedida de apresentaçäo crítica.
\end{abstract}

No início do século XX, no contexto das vanguardas artístico-literárias, poetas e artistas iniciaram um processo de destruição e renovação da linguagem literária e plástica, cujos resultados encontram-se tanto em Apollinaire quanto em Picasso, em Paul Éluard e em Marcel Duchamp. Nesse contexto, o surrealismo foi o lugar privilegiado (mas não o único) para o encontro entre dois sistemas de signos - o lingüístico e o plástico, desencadeando uma crise das imagens, na pintura, e o sonho de uma linguagem inédita, visual, na poesia (CHÉNIEUX-GENDRON, 1992:182-205). A obra de René Magritte (1898-1967), a qual pretende-se abordar neste artigo, através da apresentação de um de seus textos $-L^{\prime}$ Art de la ressemblance, é bastante significativa neste sentido.

* Recebido para publicação em novembro de 2002.

** Professora da Faculdade de Letras/UFMG, graduado em Letras pela FALE/UEMG. 
Tal pintor belga produziu uma grande parte de sua obra antes de deslocar-se para Paris, em 1927, onde encontrou o grupo surrealista. Em Bruxelas, ele já mantinha contato com os princípios deste movimento, pois, na referida cidade, atividades surrealistas se desenvolviam paralelamente às atividades parisienses desde 1926, dentro de um grupo formado por escritores, poetas e artistas como Camille Goemans, Louis Scutenaire, Paul Nougé, entre outros. Entretanto, embora Magritte tenha se familiarizado com o surrealismo antes de ir para a capital francesa, tudo indica que o contato com o movimento francês teve uma grande influência sobre sua produção nos três anos em que viveu na França, de 1927 a 1930.

Nos quadros da fase parisiense, bem como naquelès executados posteriormente, constatamos que Magritte desenvolve uma reflexão aprofundada sobre a linguagem em consonância com os textos de André Breton, poeta e teórico maior do surrealismo. Breton observa, retrospectivamente, que "o surrealismo, enquanto movimento organizado, nasceu de uma operação de grande envergadura sobre a linguagem" (BRETON, 1988:165) ${ }^{1}$ Em 1922, o poeta afirmava a necessidade de libertar as palavras de sua função utilitária dizendo que uma "química" do verbo deveria se substituir à "alquimia do verbo" proposta por Rimbaud:

Tratava-se de: 1- considerar a palavra em si; 2- estudar o mais perto possível as reações das palavras uma sobre as outras. Somente dessa forma é que poderíamos devolver à linguagem sua plena destinação, fato que, para alguns, como eu mesmo, deveria fazer avançar o conhecimento, exaltar ainda mais a vida. (BRETON, 1988:284)

Seguindo a orientação surrealista durante este período, Magritte interessou-se sobretudo pelas pesquisas de ordem plásti-

\footnotetext{
${ }^{1}$ As traduçōes para o português das citaçōes em francês são dos autores deste artigo, salvo menção contrária.
} 
ca e lingüística com o objetivo de conseguir um "efeito poético perturbador":

Os quadros pintados (...) de 1925 a 1936, foram igualmente fruto de uma busca sistemática de um efeito poético perturbador que, obtido através da encenação de objetos emprestados à realidade, dariam ao mundo real, ao qual estes objetos haviam sido emprestados, um sentido poético perturbador, por uma troca bem natural. (MAGRITTE apud GABLIK, 1978:186).

A disposição de objetos no espaço sem nenhuma relação entre si, a atmosfera onírica, a representação de formas arbitrárias, os jogos com as imagens, a ironia das legendas, características essenciais de seus quadros, buscam esse efeito poético desconcertante e, de forma lúdica, constituem "armadilhas" nas quais o espectador poderá cair de repente, uma vez que os quadros contrariam o senso-comum ao destruir toda e qualquer percepção do mundo físico e mental.

A originalidade de sua obra repousa sobre uma fusão sutil de mistério, provocação e ilusão perceptiva. Recusando o automatismo praticado pelo surrealismo, Magritte opta pelo ecletismo dos "objetos familiares", mas isolando-os do seu contexto habitual, operando um deslocamento para, em seguida, associá-los a outros objetos, de modo a nos mostrar o estranho e o insólito onde havia inicialmente só o banal, o comum. Para Magritte, o aspecto relevante da obra de arte não repousa sobre seu valor formal, mas sobre o processo intelectual que a mesma desencadeia na mente daqueles que a observam, perturbando as suas certezas visuais e teóricas mais sedimentadas.

Desse modo, Magritte faz evoluir sua própria estética e poética. Em Le Surréalisme et la peinture (1965:72), Breton reconhece essa evolução do pintor ao considerá-lo aquele que instruiu "o 
processo sistemático da imagem visual, cujas falhas ele se empenhou em mostrar, observando, ainda, o caráter dependente das figuras de linguagem e de pensamento."

As reflexões de Magritte em torno da linguagem em sua relação com o pensamento e a imagem poética podem ser verificadas em seus numerosos textos que tratam da "arte de pintar". A leitura desse material vem confirmar o que diz GABLIK (1978:11) a respeito de sua obra como um todo, ou seja, que seu estudo evidencia a integridade intelectual e o espírito questionador de um filósofo mais do que as preocupações estéticas e pictóricas de um artista.

No texto L'Art de la ressemblance, em especial - do qual apresentamos a tradução para a língua portuguesa, em seguida ${ }^{2}$ Magritte trata sobretudo da distinção entre a semelhança, (ressemblance) e a similitude (similitude), afirmando inicialmente que somente a primeira identifica-se ao "ato essencial do pensamento", ou seja, o ato de assemelhar-se, tornando-se o que o mundo lhe oferece, e de restituir o que lhe é ofertado ao mistério. Nesse sentido, a "arte de pintar" por ele definida é a "arte da semelhança", arte que não enuncia idéias, não exprime sentimentos, não se preocupa com o "invisível", mas apenas com o visível. Seu objetivo seria o de descrever "um pensamento susceptível de aparecer visivelmente". A diferença entre os dois conceitos é retomada em "L'art de peindre..."(1979:510) quando o autor afirma que a semelhança é um ato espontâneo do pensamento e não uma relação de similitude racional ou delirante.

Para contribuir com a distinção entre a semelhança e a similitude, em Magritte, torna-se indispensável citar o estudo feito

\footnotetext{
2 A tradução para o português do texto $A$ arte da semelhança (L'Art de la ressemblance. Écrits complets. Paris: Flammarion, 1979, p.655-657) foi realizada por Cídio Randolfo Geraldo Leite, bolsista PIBIC/CNPq, e insere-se no projeto de pesquisa "Palavra de artista. Tradução de textos em francês de artistas plásticos pertencentes aos movimentos dadaísta e surrealista", desenvolvido pela autora desse artigo no Departamento de Letras Românicas/FALE/UFMG.
} 
por Michel Foucault sobre as diversas versões do quadro conhecido como "o cachimbo" (La Trahison des images). Diz Foucault:

Parece-me que Magritte dissociou a semelhạça da similitude e joga esta contra aquela. A semelhança tem um "padrão": elemento original que ordena e hierarquiza a partir de si todas as cópias, cada vez mais fracas, que podem ser tiradas. Assemelhar significa uma referência primeira que prescreve e classifica. O similar se desenvolve em séries que não têm nem começo nem fim. Que é possível percorrer num sentido ou em outro, que não obedecem a nenhuma hierarquia, mas se propagam de pequenas diferenças em pequenas diferenças. $(1988: 60)$

A partir de exemplos como A Representação (1962), Decalcomania (1966) e Isto não é um cachimbo, Foucault mostra como a pintura de Magritte privilegia, por um lado, a similitude sobre a semelhança, pois esta dá ênfase à exatidão da imagem, que funciona como um "índice na direção de um modelo, de um 'padrão' soberano, único e exterior", enquanto a série das similitudes rompe com essa "monarquia ao mesmo tempo ideal e real." (1988:61)

Por outro lado, Foucault vai ao encontro de Magritte ao afirmar que a semelhança, uma vez excluída da relação entre as coisas que reenviam umas às outras, uma vez expulsa do espaço do quadro, a semelhança encontra seu espaço no pensamento: "A semelhança, que não é uma propriedade das coisas, não é própria ao pensamento?" questiona o autor (1988:64). Afirmação que reflete a de Magritte: "Só ao pensamento é dado ser semelhante; ele assemelha sendo o que vê, ouve ou conhece; torna-se o que o mundo lhe oferece." Conclui-se, portanto, que "a pintura está sem dúvida aí, nesse ponto onde vem se cortar na vertical um pensamento que está sob o modo da semelhança e das coisas que estão nas relações de similitude." (1988:64) 
Além da questão mencionada acima, o texto de Magritte-L'Art de la ressemblance - aborda a relação pintura e poesia, bem como a noção de inspiração e mistério dentro da arte de pintar preconizada pelo artista. A "arte de pintar" aproxima-se da poesia, uma vez que esta tampouco exprime idéias ou sentimentos, como bem o lembra o autor ao citar Mallarmé: "Ce n'est pas avec des idées et des sentiments que l'on fait de la poésie, c'est avec des mots." (MAGRITTE, 1979:686). Seguindo a linha do ut pictura poesis, a pintura seria a "poesia pintada", sem entretanto confundir-se com a pintura literária, adverte o autor, pois esta preocupa-se apenas com idéias e sentimentos:

A poesia escrita é invisível, a poesia pintada tem uma aparência visível. O poeta, que escreve, pensa com palavras familiares, e o pintor, que pinta, pensa com as figuras familiares do visível. A escrita é uma descrição invisível do pensamento e a pintura é sua descrição visível. (Ibidem:686)

Constata-se, de fato, a intenção de restituir à pintura o caráter poético reconhecidamente atribuído à escrita, através da noção de imagem poética; contesta-se, entretanto, a nosso ver, a prática do automatismo por parte dos surrealistas que pretendem apreender o desconhecido, afirmando-se, ao contrário, a impropriedade da pintura para representar o invisível.

No que se refere ao primeiro tema: a noção de imagem poética, esta decorre em parte daquela proposta por Pierre Reverdy (Nord-Sud, 1918) e citada no Manifesto do surrealismo por Breton:

A imagem é uma criação pura do espírito.

Ela não pode nascer de uma comparação, mas da aproximação de duas realidades mais ou menos distanciadas. Quanto mais as relações entre as duas realidades aproximadas forem longínquas e justas, mais forte será a imagem — mais 
força emotiva e realidade poética ela terá...etc. (Apud BRETON, 1988:324).

Breton discorda de Reverdy quanto à noção de "justeza" da relação estabelecida entre os termos da imagem. Para Breton, a imagem "mais forte é a que apresenta o grau de arbitrariedade o mais elevado a que levamos mais tempo para traduzir em linguagem prática." Breton declara ainda que "o valor da imagem depende da beleza da centelha obtida, dependendo, por conseguinte, da diferença de potencial entre os dois [termos] condutores"(BRETON, 1988:337-338). Nota-se a influência da célebre frase de Lautréamont (Beau comme la rencontre fortuite sur une table de dissection d'un parapluie et d'une machine à coudre) quanto à arbitrariedade dos termos que compõem a imagem, critério sobre o qual se apóia Breton.

Entretanto, para Magritte, o "choque" poético nasce da afinidade entre dois objetos, e não de seu encontro fortuito. Esses laços - ou as afinidades eletivas-são revelados pela inspiração que é o "acontecimento em que o pensamento torna-se inspirado" e este "torna-se inspirado assemelhando-se ao mundo e evocando seu mistério sem o qual não haveria nenhuma possibilidade de mundo, nem nenhuma possibilidade de pensamento." (MAGRITTE, 1979:557).

Sobre L'Empire des Lumières (1954), quadro citado em L'Art de la ressemblance, Magritte afirma: "Essa evocação da noite e do dia parece-me dotada do poder de nos surpreender e de nos encantar. Chamo esse poder: a poesia"(1979:422). A presença simultânea de um céu luminoso com nuvens claras e de uma paisagem noturna não diz respeito à realidade, esse encontro insólito releva do mistério.

Contrariando a idéia clássica de automatismo, tal como definida pelo surrealismo, Magritte afirma que as afinidades existem e o poeta as descobre, os objetos se parecem secretamente e o pin- 
tor os reúne. O poder da poesia consiste em agir profundamente sobre mecanismo de associação de imagens, contestando a lógica e fazendo surgir novas realidades que surpreendem e seduzem, conferindo ao mundo uma nova face.

Résumé: Traduction vers le portugais du texte L'Art de la ressemblance (A arte da similaridade, 1979), de l'artiste belge René Magritte, précédée d'une présentation critique.

\section{Referências bibliográficas:}

BRETON, André. Manifestes du surréalisme. Oeuvres complètes. Paris: Gallimard, 1988. v.1.

BRETON, André. Manifestes du surréalisme. Paris: Gallimard, 1963.

BRETON, André. Le Surréalisme et la peinture. Paris: 1965.

CABANNE, Pierre \& RESTANY, Pierre. L'Avant-garde au $X X^{e}$ siècle. Paris: André Balland, 1969.

CHENIEUX-GENDRON, Jacqueline. Le Surréalisme. Paris: P.U.F., 1994.

CHÉNIEUX-GENDRON, Jacqueline. Estética e Poética. O Surrealismo. São Paulo: Martins Fontes, 1992.

FOUCAULT, Michel. Isto não é um cachimbo. Tradução de Jorge Coli. Rio de Janeiro: Paz e Terra, 1988. Título original: Ceci n'est pas une pipe.

FOUCAULT, Michel. Ceci n'est pas une pipe. S.l.: Fata Morgana, 1973.

MAGRITTE, René. La Ligne de vie. Conférence au Musée des Beaux Arts d'Anvers. In GABLIK, S. Magritte. Cosmos Monographies, 1978.

MAGRITTE, René. Écrits complets. Paris: Flammarion, 1979.

MENEZES, Paulo. A trama das imagens: manifestos e pinturas no começo do século XX. São Paulo: EDUSP, 1997.

NADEAU, Maurice. História do surrealismo. São Paulo: Perspectiva, 1985. ROBERT-JONES, P. Magritte, poète visible. Paris: Laconti, 1972.

SILVEIRA, Berta Rodrigues. René Magritte. Rio de Janeiro: Civilizaçäo Brasileira, 1995.

TORCZYNER, Harry. Magritte: signos e imagens. Barcelona: Blume, 1978. 


\section{AARTE DA SEMELHANÇA}

A semelhança - da qual se fala na linguagem cotidiana - é atribuída às coisas que têm ou não uma natureza comum. Diz-se: "Assemelhar-se como duas gotas d'água" e que "a cópia se parece com o original". Esta pretensa semelhança consiste apenas em relações de similitude, distinguidas por um pensamento que examina, avalia e compara.

A semelhança identifica-se ao ato essencial do pensamento: assemelhar-se "tornando-se" o que o mundo lhe oferece e restituir - o que lhe é ofertado - ao mistério, sem o qual não haveria nenhuma possibilidade de mundo, nem nenhuma possibilidade de pensamento.

A arte de pintar - não concebida como mistificação mais ou menos inocente - não saberia enunciar idéias, nem exprimir sentimentos. As idéias e os sentimentos pertencem ao invisível. Este não tem nenhuma superioridade sobre o visível e tentar representar o invisível com imagens visíveis da pintura significa ingenuidade. A imagem de um círculo equivale a um "pensamento redon" do", mas não representa a idéia ou o sentimento do círculo, o qual caberá à filosofia definir.

A arte de pintar-que merece verdadeiramente chamar-se "a arte da semelhança" - permite descrever, pela pintura, um pensamento susceptível de aparecer visivelmente. Este pensamento compreende exclusivamente as figuras que o mundo the oferece: pessoas, astros, móveis, armas, árvores, montanhas, sólidos, inscrições, etc. Este pensamento assemelha-se quando ele une as figuras que vê, na ordem que evoca diretamente o mistério. A descrição do pensamento, que se assemelha ao mundo não separado de seu mistério, não tolera fantasia, nem originalidade. A precisão e o charme de uma imagem da semelhança perdem-se para o medíocre benefício de uma maneira "original" de pintar. $O$ "como pin- 
tar" a semelhança deve se limitar a estender as cores sobre uma superfície de tal maneira que seu aspecto efetivo se distancie e deixe aparecer a imagem do pensamento que se assemelha e que restitui o que ele vê ao mistério.

Se acontecer que fiquemos "chocados" ao ver uma imagem da semelhança, não se deve deduzir disto que ela "exprime" um sentiménto ou que enuncia uma idéia. Seria tão falso quanto crer, por exemplo, que uma cebola - que cortamos em pedaços - exprime a sensação de chorar ou que traduz a idéia de utilizá-la na cozinha.

Uma imagem não é tangível: ela não esconde nada que seja visível (nem evidentemente, invisível - este não se pode esčonder - ele é conhecido ou desconhecido). Querer "interpretar" uma imagem da semelhança a fim de exercer não se sabe qual liberdade - significa ignorá-la ou substituir-lhe uma interpretação gratuita que, por sua vez, pode ser objeto de uma série sem fim de interpretações indiferentes.

Uma imagem da semelhança não resulta da ilustração de um "assunto", nem de um "tema", nem de um símbolo. Uma imagem da semelhança é uma imagem em si, apenas o mistério não lhe é estranho.

A poesia identifica-se com a descrição do pensamento inspirado, ou seja, o pensamento que vê assemelhando-se ao mundo não separado de seu mistério. A inspiração fornece ao pintor o que é necessário pintar: por exemplo, o pensamento cujos termos são um cachimbo e a inscrição "isto não é um cachimbo", ou então o pensamento constituído por uma paisagem noturna sob um céu ensolarado.

"De direito" tais pensamentos evocam o mistério, enquanto "de fato" somente o mistério está presente - mas não manifesto lá onde um cachimbo é colocado sobre um cinzeiro ou onde uma paisagem noturna se acha sob um céu estrelado. 
A semelhança não se preocupa em concordar ou desafiar "o senso comum", que concorda passivamente com aquilo que o mundo tem de incongruente. A semelhança - que somente a inspiração pode fazer surgir - manifesta o mistério que o mundo incongruente da razão é incapaz de sugerir.

"Historicamente", a arte da semelhança surge com o fim das pesquisas formais impressionistas, futuristas, cubistas e abstratas do século XX. Não faltava um certo charme da novidade à confusão específica dessas pesquisas, que se queriam libertadoras de uma arte limitada à ilustração de "assuntos" escolhidos dentro de um repertório conhecido. A arte da semelhança geraria confusão como novidade: o que ela coloca em questão não é nada menos que o mistério - que não tem nada de histórico - da vida e da morte.

\section{**}

As palavras que nomeiam convenientemente, que são os títulos das imagens da semelhança, deixam de ser familiares ou estranhas. É necessário a inspiração para dizê-las e para entendêlas.

\section{L'ART DE LA RESSEMBLANCE}

La ressemblance - dont il est question dans le langage quotidien - est attribuée à des choses ayant ou n'ayant pas de commune nature. On dit: "Se ressembler comme deux gouttes d'eau" et "que le faux ressemble à l'authentique". Cette prétendue ressemblance ne consiste guère qu'en des rapports de similitude, distingués par une pensée qui examine, évalue et compare.

La ressemblance s'identifie à l'acte essentiel de la pensée: celui de ressembler en devenant ce que le monde lui offre et de restituer - ce que lui est offert - au mystère sans lequel il n'y aurait aucune possibilité de monde ni aucune possibilité de pensée. 
L'art de peindre - non conçu comme mystification plus ou moins innocente - ne saurait énoncer des idées ni exprimer des sentiments. Les idées et les sentiments appartiennent à l'invisible. Celui-ci n'a aucune supériorité sur le visible et tenter de représenter l'invisible avec les images visibles de la peinture relève de la niaiserie. L'image d'un cercle équivaut à une "pensée ronde" mais ne représente pas l'idée ou le sentiment du cercle qu'il appartient à la philosophie de définir.

L'art de peindre - qui mérite vraiment de s'appeler "L'art de la ressemblance" - permet de décrire, par la peinture, une pensée susceptible d'apparaître visiblement. Cette pensée comprend exclusivement les figures visibles que le monde lui offre: personnes, astres, meubles, armes, arbres, montagnes, solides, inscriptions, etc. Cette pensée ressemble lorsqu'elle unit les figures qu'elle voit, dans l'orde [sic] qui évoque directement le mystère. La description de la pensée, qui ressemble au monde non séparé de son mystère, ne tolère pas de fantaisie ni d'originalité. La précision et le charme d'une image de la ressemblance se perdent au médiocre bénéfice d'une manière «originale» de peindre. «Le comment peindre» la ressemblance doit se borner à étendre des couleurs sur une surface, de telle sorte que leur aspect effectif s'éloigne et laisse apparaître l'image de la pensée qui ressemble et qui restitue ce qu'elle voit au mystère.

S'il advient que l'on soit "frappé" en regardant une image de la ressemblance, il n'en faut pas déduire qu'elle "exprime" un sentiment ou qu'elle énonce une idée. Ce serait aussi faux que de croire, par exemple, qu'un oignon - que l'on coupe en morceaux - exprime la sensation de pleurer ou qu'il énonce l'idée de l'utiliser dans la cuisine.

Une image n'est pas tangible: elle ne cache rien qui soit visible (ni, évidemment d'invisible - celui-ci ne peut se cacher - il est connu ou il est inconnu). Vouloir "interpréter" une image de la ressemblance, afin d'exercer l'on ne sait quelle liberté - c'est 
l'ignorer ou lui substituer une interprétation gratuite qui, à son tour, peut faire l'objet d'une série sans fin d'interprétations indifférentes.

Une image de la ressemblance ne résulte pas de l'illustration d'un "sujet", ni d'un "thème", ni d'un symbole. Une image de la ressemblance est une image en soi, seul le mystère ne lui est pas étranger.

;:

La poésie s'identifie à la description de la pensée inspirée, c'est-à-dire de la pensée qui voit en ressemblant au monde non séparé de son mystère. L'inspiration donne au peintre ce qu'il faut peindre: par exemple, la pensée dont les termes sont une pipe et l'inscription "ceci n'est pas une pipe" ou bien la pensée constituée par une paysage nocturne sous un ciel ensoleillé. "En droit" de telles pensées évoquent le mystère, alors "qu'en fait" seulement, le mystère est présent - mais non manifeste - là où une pipe est posée sur un cendrier ou là où un paysage nocturne se trouve sous un ciel étoilé.

La ressemblance ne se soucie pas de s'accorder ou de défier "le sens commun" qui s'accorde passivement avec ce que le monde a d'incongru. La ressemblance - que l'inspiration seule peut faire surgir - manifeste le mystère que le monde incongru de la raison est incapable de suggérer.

"Historiquemen", l'art de la ressemblance apparaît avec la fin des recherches formelles impresionistes [sic], futuristes, cubistes et abstraites du $X^{e}$ siècle. La confusion spécifique de ces recherches, qui se voulaient libératrices d'un art limité à l'illustration de «sujets» choisis dans un répertoire connu, ne manquaient [sic] pas d'un certain charme de la nouveauté. L'art de la ressemblance serait considéré avec confusion comme une nouveauté: ce qu'il met en question n'est rien de moins que le mystère - qui n'a rien d'historique - de la vie et de la mort. 
Les mots qui nomment convenablement, qui sont des titres des images de la ressemblance, cessent de demeurer familiers ou étranges. Il faut l'inspiration pour les dire et pour les entendre. 